\title{
Insulin resistant subjects lack islet adaptation to short-term dexamethasone-induced reduction in insulin sensitivity
}

\author{
H. Larsson, B. Ahrén \\ Department of Medicine, Lund University, Malmö, Sweden
}

\section{Abstract}

Aims/hypothesis. To establish whether islet compensation to deterioration of insulin action depends on inherent insulin sensitivity.

Methods. We examined insulin and glucagon secretion after iv arginine $(5 \mathrm{~g})$ at fasting, 14 and greater than $25 \mathrm{mmol} / \mathrm{l}$ glucose concentrations before and after lowering of insulin sensitivity by oral dexamethasone ( $3 \mathrm{mg}$ twice daily for $21 / 2$ days) in 10 women with normal glucose tolerance, aged 58 or 59 years. Five women had high insulin sensitivity as shown by euglycaemic, hyperinsulinaemic clamp $(99 \pm 12 \mathrm{nmol}$ glucose $\cdot \mathrm{kg}$ body weight ${ }^{-1} \cdot \mathrm{min}^{-1} / \mathrm{pmol}$ insulin $\cdot \mathrm{l}^{-1}$; means \pm SD) whereas five women had low insulin sensitivity $\left(34 \pm 15 \mathrm{nmol}\right.$ glucose $\cdot \mathrm{kg}$ body weight ${ }^{-1}$. $\mathrm{min}^{-1} / \mathrm{pmol}$ insulin $\cdot \mathrm{l}^{-1}$ ).

Results. Dexamethasone reduced insulin sensitivity in both groups. Fasting insulin concentration increased by dexamethasone in high insulin sensitivity $(72 \pm 10$ vs $49 \pm 9 \mathrm{pmol} / 1, p=0.043$ ) but not in low insulin sensitivity $(148 \pm 63$ vs $145 \pm 78 \mathrm{pmol} / \mathrm{l})$ whereas the fast- ing glucose concentration increased in low insulin sensitivity $(6.5 \pm 0.8$ vs $5.8 \pm 0.6 \mathrm{mmol} / \mathrm{l}, p=0.043)$ but not in high insulin sensitivity $(5.3 \pm 0.8$ vs $5.3 \pm 0.6 \mathrm{mmol} / \mathrm{l})$. Fasting glucagon concentration was not changed. Plasma insulin concentrations after raising glucose to 14 and more than $25 \mathrm{mmol} / \mathrm{l}$ and the insulin response to arginine at more than $25 \mathrm{mmol} / \mathrm{l}$ glucose were increased by dexamethasone in high insulin sensitivity $(p<0.05)$ but not changed by dexamethasone in low insulin sensitivity. Furthermore, in high but not in low insulin sensitivity, dexamethasone reduced the glucagon response to arginine $(p=0.043)$.

Conclusion/interpretation. The results show that adaptation in islets function to dexamethasone-induced short-term reduction in insulin sensitivity is lacking in subjects with low inherent insulin sensitivity. [Diabetologia (1999) 42: 936-943]

Keywords Insulin secretion, glucagon secretion, islet function, insulin sensitivity, dexamethasone.
It is known that islet function is reciprocally related to peripheral insulin sensitivity, in that insulin secretion is adaptively increased in insulin resistance [1-7]. This relation is disturbed in subjects with Type II (non-insulin-dependent) diabetes mellitus and impaired glucose tolerance [2,5-11]. This shows that islet dysfunction is a pathogenetic factor for Type II

Received: 26 January 1999 and in revised form: 1 March 1999

Corresponding author: B. Ahrén MD, Department of Medicine, Malmö University Hospital, S-205 02 MALMÖ, Sweden diabetes as has been proposed [12-14]. The intimate relation between insulin secretion and insulin sensitivity suggests that it is also the islet capacity in relation to the ambient insulin sensitivity which is the critical factor for development of glucose intolerance and diabetes, rather than the absolute insulin secretory capacity in itself.

The relation between insulin sensitivity and insulin secretion has a hyperbolic function [1-3, 7]. This indicates that as long as the product of insulin secretion times insulin sensitivity remains constant, normal glucose tolerance is preserved [3]. From this relation follows also that subjects with low insulin sensitivity 
Table 1. Clinical characteristics of the subjects

\begin{tabular}{|c|c|c|c|}
\hline Characteristic & $\begin{array}{l}\text { Subjects with low } \\
\text { insulin sensitivity } \\
(n=5)\end{array}$ & $\begin{array}{l}\text { Subjects with high } \\
\text { insulin sensitivity } \\
(n=5)\end{array}$ & $p$ value \\
\hline Age (years) & $58.7 \pm 0.6$ & $58.6 \pm 0.4$ & NS \\
\hline Body mass index $\left(\mathrm{kg} / \mathrm{m}^{2}\right)$ & $30.4 \pm 6.4$ & $24.3 \pm 3.6$ & $\mathrm{NS}(p=0.101)$ \\
\hline Waist : hip ratio & $0.84 \pm 0.06$ & $0.75 \pm 0.03$ & $\mathrm{NS}(p=0.057)$ \\
\hline Fasting blood glucose (mmol/l) & $5.0 \pm 0.7$ & $4.7 \pm 0.5$ & NS \\
\hline 2 -h glucose at OGTT $(\mathrm{mmol} / \mathrm{l})$ & $7.3 \pm 1.6$ & $7.2 \pm 1.7$ & NS \\
\hline $\mathrm{HbA}_{1 \mathrm{c}}(\%)($ reference range $<5.5 \%)$ & $5.0 \pm 0.5$ & $5.0 \pm 0.5$ & NS \\
\hline
\end{tabular}

$P$-value indicates the probability level of random difference between the groups. Data are given as means \pm SD

have to respond with a more pronounced increase in insulin secretion than subjects with high insulin sensitivity when insulin sensitivity is similarly reduced, to maintain normal glucose tolerance. Whether this actually occurs following short-term changes in insulin sensitivity is not known, however, largely because studies showing the relation between insulin sensitivity and insulin secretion in normal subjects have been cross-sectional studies of groups of subjects. Furthermore, previous studies on short-term reduction of insulin sensitivity in individual humans, by means of dexamethasone and nicotinic acid, have shown that islet function is indeed adaptated to increased insulin secretion $[15,16]$. These studies have, however, not taken into account the individual differences in insulin sensitivity between subjects, and therefore, these studies could not establish whether the islet adaptation to insulin resistance is dependent on the inherent insulin sensitivity.

Knowledge on islet regulation by short-term changes in insulin secretion is thus lacking in individual humans. This is important to establish because it will provide insight into the mechanism of impaired glucose tolerance or diabetes under conditions of reduced insulin sensitivity, such as pregnancy or treatment with glucocorticoids. The present study therefore compared the islet adaptation to about $50 \%$ reduction in insulin sensitivity in healthy subjects with high compared with low insulin sensitivity. The subjects were recruited from a population study in healthy postmenopausal women (with normal glucose tolerance) who had undergone a euglycaemic, hyperinsulinaemic clamp to establish their insulin sensitivity [6]. From this study, five subjects with high and five subjects with low insulin sensitivity were selected. Islet function was evaluated by the glucose-dependent arginine stimulation test for determining insulin and glucagon secretion [17] which we evaluated recently [18]. Insulin sensitivity was reduced by means of dexamethasone, which was given to the subjects for $21 / 2$ days, after which new tests for determining insulin sensitivity and islet function were carried out.

\section{Subjects and methods}

Subjects. We studied 10 postmenopausal Caucasian women aged 58 or 59 years. The subjects belonged to a study population of non-diabetic women who underwent a euglycaemic, hyperinsulinaemic clamp to establish their insulin sensitivity [6]. In the study group of 108 women, insulin sensitivity had a normal distribution with a mean \pm SD of $71.8 \pm 30.5$ nmol glucose $\cdot \mathrm{kg}$ body weight ${ }^{-1} \cdot \mathrm{min}^{-1} / \mathrm{pmol}$ insulin $\cdot \mathrm{l}^{-1}$. The ten women selected for this study were chosen because five of them had low insulin sensitivity whereas the other five had high insulin sensitivity. The five women with high insulin sensitivity belonged to the highest distribution quartile of all women $(>88$ nmol glucose $\cdot \mathrm{kg}$ body $\mathrm{weight}^{-1} \cdot \mathrm{min}^{-1} / \mathrm{pmol}$ insulin $\left.\cdot \mathrm{l}^{-1}\right)$, whereas the five women with low insulin sensitivity belonged to the lowest distribution quartile of all women $(<50 \mathrm{nmol}$ glucose $\cdot \mathrm{kg}$ body weight ${ }^{-1} \cdot \mathrm{min}^{-1} / \mathrm{pmol}$ insulin $\left.\cdot \mathrm{l}^{-1}\right)$. All women were healthy with normal glucose tolerance as shown by an oral glucose $(75 \mathrm{~g})$ tolerance test according to WHO criteria [19]. None of the women was taking any medication known to affect carbohydrate metabolism. Table 1 shows the clinical characteristics of the subjects in the two groups. The study was approved by the ethics committee at Lund University. All subjects gave written informed consent before joining the study.

Research design. Each subject participated in four separate tests: the euglycaemic, hyperinsulinaemic clamp and the glucose-dependent arginine-stimulation test with or without prior treatment with oral dexamethasone (Dexacortal, Organon, Oss, The Netherlands; $3 \mathrm{mg}$ in the morning and evening for the 2 days before the tests and $3 \mathrm{mg}$ at 0800 hours in the morning of the test, i.e. a total of $15 \mathrm{mg}$ dexamethasone). The four tests were done with a 2-4 weeks interval between each test.

Insulin sensitivity. Insulin sensitivity was determined with the euglycaemic, hyperinsulinaemic clamp method [20]. After an overnight fast, intravenous catheters were inserted into antecubital veins in both arms. One arm was used for infusion of glucose and insulin. The contralateral arm was used for intermittent sampling, and the catheter was kept patent with slow infusion of $0.9 \%$ saline. Base-line samples of glucose and insulin were taken. A primed-constant infusion of insulin (Actrapid $100 \mathrm{U} / \mathrm{ml}$, Novo Nordisk, Bagsvaerd, Denmark) with a constant infusion rate of $0.28 \mathrm{nmol} / \mathrm{m}^{2}$ body surface area/min was started. After $4 \mathrm{~min}$, a variable rate $20 \%$ glucose infusion was added and its infusion rate was adjusted manually throughout the clamp procedure to maintain the blood glucose concentration at $5.0 \mathrm{mmol} / \mathrm{l}$. Blood glucose was determined at bedside 
Table 2. Results of the euglycaemic hyperinsulinaemic clamp with or without treatment with dexamethasone (DEX) in healthy women with low or high insulin sensitivity

\begin{tabular}{|c|c|c|c|c|}
\hline \multirow[t]{2}{*}{ Variable } & \multicolumn{2}{|c|}{ Low insulin sensitivity $(n=5)$} & \multicolumn{2}{|c|}{ High insulin sensitivity $(n=5)$} \\
\hline & Without DEX & With DEX & Without DEX & With DEX \\
\hline Serum insulin during clamp (pmol/l) & $842 \pm 180$ & $832 \pm 133$ & $697 \pm 106$ & $643 \pm 166$ \\
\hline Insulin sensitivity ${ }^{\mathrm{b}}$ & $34 \pm 15^{\mathrm{a}}$ & $12 \pm 7$ & $99 \pm 12^{\mathrm{a}}$ & $49 \pm 16$ \\
\hline
\end{tabular}

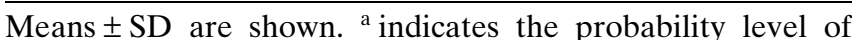
$p=0.043$ of the random difference within the respective study groups with vs without treatment with dexamethasone as ob- tained by Wilcoxon signed rank test for two related samples. ${ }^{\mathrm{b}} \mathrm{nmol}$ glucose $\cdot \mathrm{kg}$ body weight ${ }^{-1} \cdot \mathrm{min}^{-1} / \mathrm{pmol}$ insulin $\cdot \mathrm{1}^{-1}$ every $5 \mathrm{~min}$. Samples for analysis of the insulin concentration obtained were taken at 60 and $120 \mathrm{~min}$.

Islet function. Insulin and glucagon secretion were determined with intravenous arginine stimulation at three glucose concentrations (fasting, 14 and $>25 \mathrm{mmol} / \mathrm{l}$ ), as described previously $[17,18]$. After an overnight fast, intravenous catheters were inserted into antecubital veins in both arms. One arm was used for infusion of glucose and the other arm for intermittent sampling. The sampling catheter was kept patent by slow infusion of $0.9 \%$ saline when not used. Base-line samples were taken at -5 and $-2 \mathrm{~min}$. A dose of arginine hydrochloride $(5 \mathrm{~g})$, which produces maximum stimulation, was then injected intravenously over $45 \mathrm{~s}$. Samples were taken at $+2,+3,+4$ and +5 min. A variable-rate $20 \%$ glucose infusion was then initiated to raise and maintain glucose at $13-15 \mathrm{mmol} / \mathrm{l}$. Blood glucose was determined every $5 \mathrm{~min}$ at bed-side and the glucose infusion adjusted to reach the desired blood glucose concentration of $13-15 \mathrm{mmol} / \mathrm{l}$ in $20-25 \mathrm{~min}$. New base-line samples were taken, then arginine (5 g) was again injected and samples taken at $+2,+3,+4$ and +5 min. A 2.5 -h resting period was then allowed to avoid the well-known priming effect of hyperglycaemia [21, 22]. After the pause, base-line samples were again obtained. Then a high-speed $(900 \mathrm{ml} / \mathrm{h}) 20 \%$ glucose infusion during $25-30 \mathrm{~min}$ was used to raise glucose to more than $25 \mathrm{mmol} / \mathrm{l}$, as determined at bed-side. At this blood glucose concentration, new base-line samples were taken and arginine $(5 \mathrm{~g})$ injected, followed by final samples taken at $+2,+3,+4$ and +5 min.

Analyses. Blood glucose concentration was determined at bedside by the glucose dehydrogenase technique with a Hemocue (Hemocue AB, Ängelholm, Sweden) during the hyperinsulinaemic, euglycaemic clamp and with an Accutrend (Boehringer Mannheim Scandinavia AB, Bromma, Sweden) during the arginine test. The Hemocue showed an intra-assay coefficient of variation of $2.1 \%$ at $5 \mathrm{mmol} / \mathrm{l}$ glucose and the accuracy when compared with standard determined with the glucose oxidase method was $101 \pm 3 \%$ with a regression of $r=0.99$. The accuracy for the Accutrend compared with standard determined with the glucose oxidase method was $102 \pm 3 \%$ with a regression of $r=0.99$. Blood samples for analysis of insulin, glucagon and glucose from the arginine and clamp studies, and glucose from the oral glucose tolerance test were immediately centrifuged $\left(3000 \mathrm{rpm} ; 10 \mathrm{~min} ; 4^{\circ} \mathrm{C}\right)$ and serum or plasma frozen at $-20^{\circ} \mathrm{C}$ until analysis in duplicate. Serum insulin and plasma glucagon concentrations were analysed with doubleantibody radioimmunoassay techniques. For the insulin assay, guinea-pig anti-human insulin antibodies, human insulin standard and mono- ${ }^{125}$ I-Tyr-human insulin (Linco Res., St Charles, Mo., USA) were used. The assay is specific for insulin, with no cross-reactivity $(<0.2 \%)$ with intact proinsulin or des-31,32proinsulin. The intra-assay and interassay coefficients of varia- tion $(\mathrm{CV})$ of the insulin assay is less than $3 \%$. Samples for analysis of glucagon were obtained in pre-chilled test tubes containing $0.084 \mathrm{ml}$ EDTA $(0.34 \mathrm{~mol} / \mathrm{l})$ and aprotinin $(250 \mathrm{kal}-$ likrein inhibiting units/ml blood, Bayer, Leverkusen, Germany). Analysis of glucagon concentration was done by doubleantibody radioimmunoassay using guinea-pig antihuman glucagon antibodies specific for pancreatic glucagon, ${ }^{125}$ I-glucagon as tracer and glucagon standard (Linco). Plasma glucose concentrations were analysed using the glucose oxidase method. Concentrations of insulin, glucagon and glucose from the arginine and clamp studies were taken as means of the duplicate samples.

Calculations and statistics. Data are presented as means $\pm \mathrm{SD}$, unless otherwise noted. For calculation of insulin sensitivity, a steady state condition was assumed during the second hour of the clamp. Calculations were done as described previously [20]. Thus, insulin sensitivity (nmol glucose $\cdot \mathrm{kg}$ body weight ${ }^{-1} \cdot \min ^{-1} / \mathrm{pmol} \mathrm{insulin} \cdot \mathrm{l}^{-1}$ ) was taken as the glucose infusion rate during the second hour of the clamp divided by the measured mean insulin concentration during the second hour of the clamp. The arginine-induced insulin responses (AIR; "acute insulin response") were calculated as the mean of the samples taken at +2 to +5 min minus the mean prestimulus insulin concentration. The slope between AIR at fasting glucose and at glucose $14 \mathrm{mmol} / \mathrm{l}\left(\right.$ slope $_{\mathrm{AIR}}=\Delta \mathrm{AIR} / \Delta$ glucose) was calculated as a measure of glucose potentiation of insulin secretion $[14,23]$ using the plasma glucose values that had been determined. The arginine-induced glucagon respons-

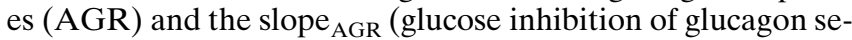
cretion) were calculated in the same manner. Statistical analyses were done by the SPSS for Windows system (SPSS, Chicago, Ill., USA). Effects of dexamethasone within each group were tested with Wilcoxon signed rank test.

\section{Results}

Glucose, insulin and insulin sensitivity. Dexamethasone reduced insulin sensitivity by the same degree in both groups, by $50 \pm 20 \%$ in those with high insulin sensitivity $(p=0.043)$ and by $66 \pm 11 \%$ in those with low insulin sensitivity $(p=0.043)$ (Table 2$)$. At the same time, fasting plasma glucose concentration was increased by dexamethasone in subjects with low insulin sensitivity ( $p=0.043$; Table 3 ) but not in those with high insulin sensitivity. Fasting serum insulin concentrations were, in contrast, increased by dexamethasone in subjects with high insulin sensitivity $(p=0.043$; Table 3$)$ but not in subjects with low insu- 
Table 3. Results of the glucose-dependent arginine stimulation test with or without treatment with dexamethasone (DEX) in healthy women with low $(n=5)$ or high insulin sensitivity $(n=5)$

\begin{tabular}{|c|c|c|c|c|}
\hline \multirow[t]{2}{*}{ Variable } & \multicolumn{2}{|c|}{ Low insulin sensitivity } & \multicolumn{2}{|c|}{ High insulin sensitivity } \\
\hline & Without DEX & With DEX & Without DEX & With DEX \\
\hline Fasting plasma glucose $(\mathrm{mmol} / \mathrm{l})$ & $5.8 \pm 0.6^{\mathrm{a}}$ & $6.5 \pm 0.8$ & $5.3 \pm 0.6$ & $5.3 \pm 0.8$ \\
\hline Serum insulin $(\mathrm{pmol} / \mathrm{l})$ at PG 14 & $297 \pm 196$ & $323 \pm 143$ & $192 \pm 86^{\mathrm{a}}$ & $270 \pm 71$ \\
\hline Serum insulin $(\mathrm{pmol} / \mathrm{l})$ at $\mathrm{PG}>25$ & $699 \pm 448$ & $854 \pm 414$ & $360 \pm 145^{\mathrm{a}}$ & $532 \pm 301$ \\
\hline Fasting plasma glucagon (ng/l) & $74 \pm 25$ & $76 \pm 19$ & $60 \pm 7$ & $64 \pm 12$ \\
\hline Plasma glucagon (ng/l) at PG 14 & $51 \pm 17$ & $53 \pm 11$ & $41 \pm 11$ & $46 \pm 9$ \\
\hline Slope $_{\text {AGR }}$ (ng glucagon/mmol glucose $)$ & $-2.9 \pm 1.7$ & $-2.8 \pm 0.8$ & $-7.1 \pm 2.2$ & $-7.6 \pm 2.6$ \\
\hline
\end{tabular}

$\mathrm{PG}$ indicates plasma glucose. Means $\pm \mathrm{SD}$ are shown. ${ }^{\mathrm{a}}$ indicates the probability level of $p=0.043$ of random difference within the respective study groups with vs without treatment with dexamethasone as obtained by Wilcoxon signed rank test for two related samples lin sensitivity. Fasting plasma glucagon concentration was not changed by dexamethasone in any of the two groups. Hence, subjects with low insulin sensitivity did not show increased serum insulin concentration upon a further deterioration of insulin sensitivity, which was accompanied by manifest hyperglycaemia, whereas subjects with high insulin sensitivity had increased serum insulin concentration and maintained normoglycaemia.

Islet function. Figure 1 shows the AIR and AGR to arginine, respectively, at the three different glucose concentrations in the subjects with low and high insulin sensitivity with or without treatment with dexamethasone and Table 3 shows the serum insulin and glucagon concentrations as well as slope $\mathrm{AIR}_{\mathrm{R}}$ and slope $_{\mathrm{AGR}}$ during the tests. In subjects with low insulin sensitivity, dexamethasone did not change the increase in serum insulin induced by increased concentration of circulating glucose, the AIRs to arginine

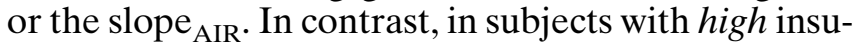
lin sensitivity, dexamethasone potentiated the increase in serum insulin concentration induced by raising circulating glucose, the AIR to arginine at greater than $25 \mathrm{mmol} / \mathrm{l}$ glucose and the slope $\mathrm{AIR}_{\mathrm{A}}(p=0.043)$. Furthermore, in subjects with low insulin sensitivity, dexamethasone did not change the AGRs to arginine or the slope $\mathrm{AGR}_{\mathrm{AG}}$, whereas in subjects with high insulin sensitivity, dexamethasone reduced the AGRs to arginine at all glucose concentrations $(p=0.043)$. The reduction in plasma glucagon concentration induced by the increase of circulating glucose concentration was not affected by dexamethasone in any of the two study groups.

Relation between insulin sensitivity and islet function. Figure 2 shows the change in the AIR to arginine at glucose greater than $25 \mathrm{mmol} / \mathrm{l}$ (maximum AIR = $A_{\text {IR }}$ MAX) in the two study groups with or without treatment with dexamethasone in relation to insulin sensitivity. It is seen that in subjects with high insulin sensitivity, the reduction in insulin sensitivity was accompanied by an increased $\mathrm{AIR}_{\mathrm{MAX}}$ whereas in subjects with low insulin sensitivity, no such compensation was seen. This difference in islet adaptation can also be illustrated by multiplying insulin sensitivity times $\mathrm{AIR}_{\mathrm{MAX}}$. This product was not changed by dexamethasone in subjects with high insulin sensitivity $\left(103 \pm 12 \mu \mathrm{mol} \cdot \mathrm{kg}^{-1} \cdot \mathrm{min}^{-1}\right.$ before dexamethasone vs $73 \pm 8 \mu \mathrm{mol} \cdot \mathrm{kg}^{-1} \cdot \mathrm{min}^{-1}$ after dexamethasone $=$ NS), since insulin secretion compensated the reduced insulin sensitivity but fell in subjects with low insulin sensitivity $\left(63 \pm 10\right.$ vs $21 \pm 4 \mu \mathrm{mol} \cdot \mathrm{kg}^{-1}$. $\left.\min ^{-1}, p=0.043\right)$.

\section{Discussion}

This study shows that the adaptively increased insulin secretion which occurs as a result of short-term reduction in insulin sensitivity is lacking in subjects with low insulin sensitivity even in healthy subjects with normal glucose tolerance. This result has bearing both for the understanding of the intimate relation between insulin secretion and insulin sensitivity in subjects with normal glucose tolerance as well as for the understanding of development of glucose intolerance and diabetes under conditions of insulin resistance. Several previous studies have examined the relation between insulin sensitivity and insulin secretion in different groups of subjects and it has been convincingly shown that an inverse relation between these variables exists [1-7]. As was predicted [1] and has been shown [2], the inverse relation between insulin sensitivity and insulin secretion has a hyperbolic relation. By comparing different groups of subjects in cross-sectional studies, it has also been shown that subjects with Type II diabetes or who are at risk of developing Type II diabetes, for example subjects with impaired glucose tolerance, show a disturbance in this relation in that insulin secretion is not adequate for the ambient insulin sensitivity [2, 5-11]. There- 

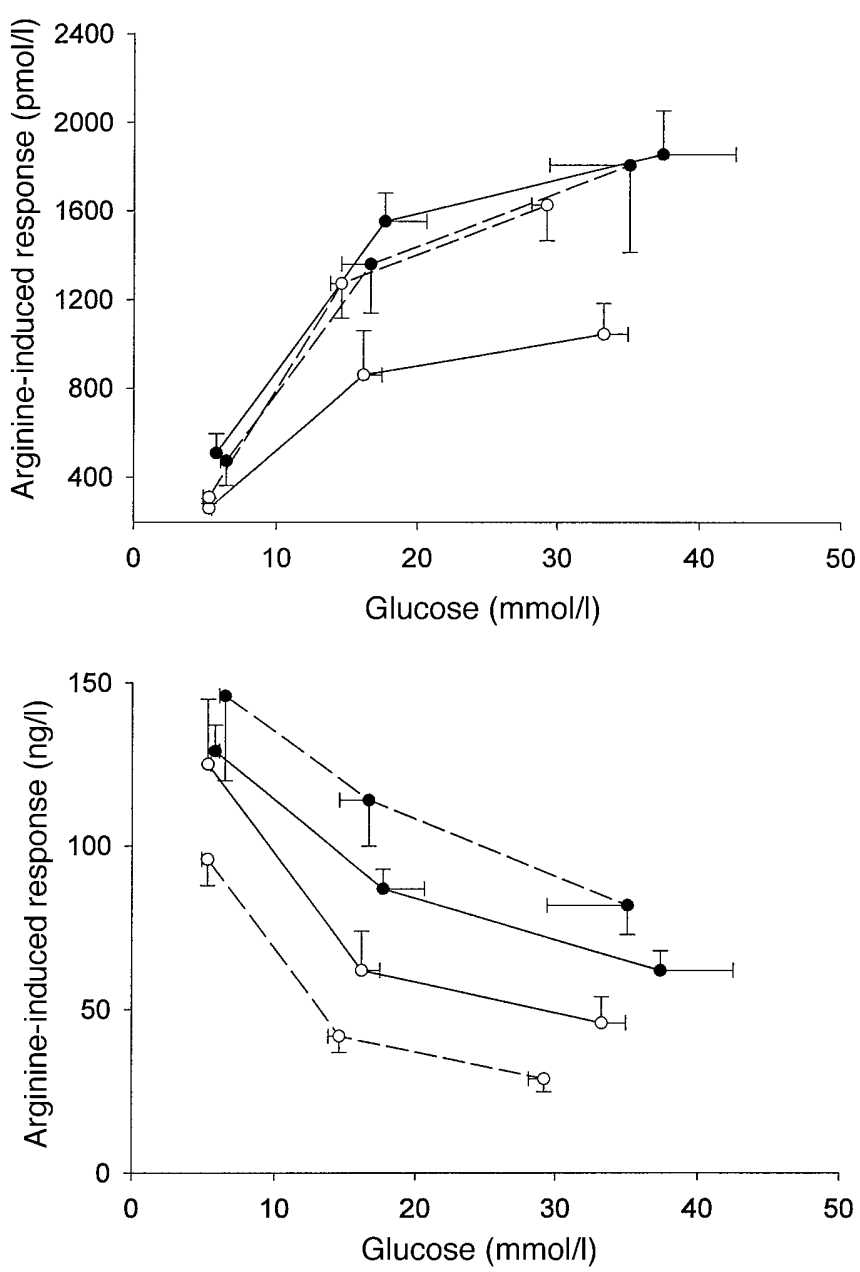

Fig. 1. Arginine-induced insulin response (AIR; upper panel) and arginine-induced glucagon response (AGR; lower panel) (5 $\mathrm{g}$ arginine iv, $2-5 \mathrm{~min}$ post-load increase) at three glucose concentrations (fasting, 14 and $>25 \mathrm{mmol} / \mathrm{l}$ ) in postmenopausal women with low $(n=5)$ or high $(n=5)$ insulin sensitivity with or without a $21 / 2$ day treatment with dexamethasone ( $3 \mathrm{mg}$ twice daily, total $15 \mathrm{mg}$ dexamethasone). Values are means \pm SEM. - - = low insulin sensitivity without dexamethasone; --- --- low insulin sensitivity with dexamethasone; $-1-=$ high insulin sensitivity without dexamethasone; - - - - - = high insulin sensitivity with dexamethasone

fore, by comparing the relation between insulin sensitivity and insulin secretion in cross-sectional groups of subjects it is possible to establish the degree of risk for developing glucose intolerance.

For the individual subject it might, however, be more important, for the risk of developing glucose intolerance, how islet function copes with a change in insulin sensitivity over time. This has been the subject of a few studies before. A first study showed in healthy young men that a $21 / 2$ day treatment with dexamethasone adaptively increased insulin secretion induced by glucose and the $\beta$-adrenoceptor agonist isoproterenol at glucose concentrations of about $14 \mathrm{mmol} / \mathrm{l}$ [15]. Furthermore, an increased AIR to arginine after induction of insulin resistance with nic-

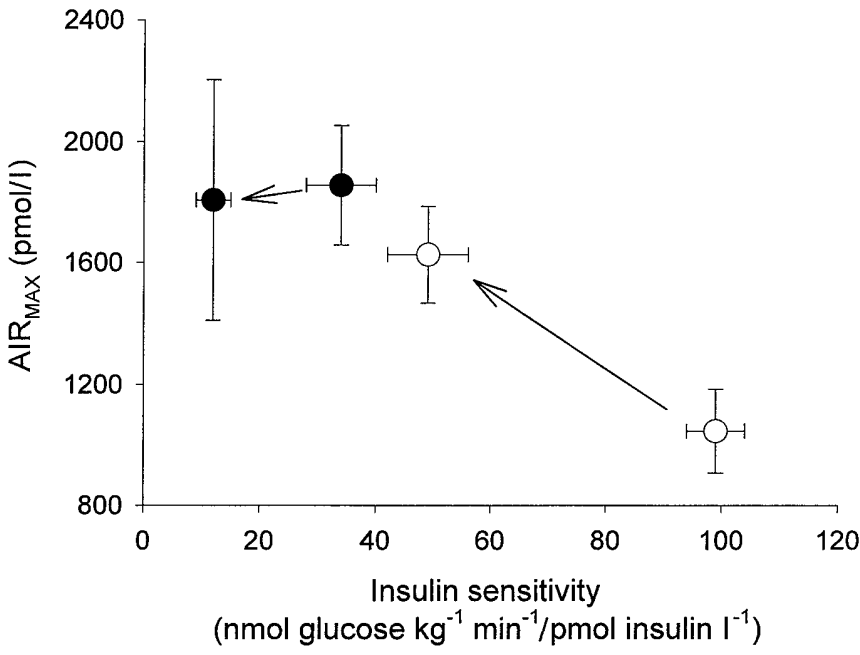

Fig. 2. Arginine-induced insulin response (5 $\mathrm{g}$ arginine iv; 2-5 min post-load increase) at glucose concentration $>25 \mathrm{mmol} / \mathrm{l}$ vs insulin sensitivity, as determined by euglycaemic hyperinsulinaemic clamp, in postmenopausal women with low $(n=5)$ or high $(n=5)$ insulin sensitivity with or without a 2 1/2 day treatment with dexamethasone (3 mg twice daily, total $15 \mathrm{mg}$ dexamethasone). Values are means \pm SEM. $=$ low insulin sensitivity; $\bigcirc$ = high insulin sensitivity; arrows indicate the change obtained by dexamethasone

otinic acid in healthy men has been shown [16]. Moreover, insulin resistance in pregnancy has been shown to be associated with increased insulin secretion $[24,25]$. Conversely, exercise training in older adults resulted in increased insulin sensitivity followed by reduced insulin secretion [26]. Similarly, we have shown that induction of insulin resistance in mice by means of high-fat diet results in a potentiated insulin secretory response to several different nonglucose stimuli, although the response to glucose is impaired [27]. Although these studies indicate that lowering of insulin sensitivity is followed by increased insulin secretion, they could not answer whether the regulatory ability was different in subjects with low compared with high insulin sensitivity, since the groups were not stratified for insulin sensitivity.

In this study we examined subjects with low compared with high insulin sensitivity. We used dexamethasone to lower insulin sensitivity because it is known to considerably reduce insulin action within a 2-day period and therefore to be suitable for studies on effects of insulin induced under short-term conditions [15, 28-30]. Corticosteroids have been shown to inhibit insulin secretion, as shown both in perfused rat pancreas and in isolated islets [31-34]. Therefore, although still possible, a potentiated insulin secretion after the induction of low insulin sensitivity in vivo, is most likely not caused by a direct stimulatory islet effect of dexamethasone but rather indirectly through the adaptive islet regulation by insulin resistance. A remaining possibility, without as yet any direct evidence is, however, that dexamethasone would influ- 
ence islet function differently in subjects with low compared with high insulin sensitivity. For the determination of islet function, we used the glucose-dependent arginine-stimulation test $[17,18]$. This test uses arginine to stimulate insulin and glucagon secretion at three different glucose concentrations. This method enables calculations of insulin and glucagon secretory capacity as well as the glucose potentiation of insulin secretion and the glucose inhibition of glucagon secretion and therefore gives multifaceted information of islet function. We showed recently that the method exhibits a good reproducibility [18].

Our results show that in subjects with high insulin sensitivity, a pronounced reduction of the insulin sensitivity by dexamethasone is accompanied by increased insulin secretory response to arginine at high glucose concentrations as well as by increased plasma insulin concentrations after raising the glucose concentrations and an increased slope ${ }_{\mathrm{AIR}}$, which are all indications of increased beta-cell secretion. Hence, in these subjects, a beta-cell adaptation to reduction in insulin sensitivity has occurred. In contrast to these findings, the subjects with low insulin sensitivity did not show any increase in beta-cell secretion in spite of a $66 \%$ reduction in insulin sensitivity. These subjects did not further increase their baseline hyperinsulinaemia whereas increased baseline insulin was achieved in subjects with high insulin sensitivity. Consequently, fasting glucose concentrations increased in subjects with low but not in those with high insulin sensitivity. It was previously shown that low capacity for insulin secretion is a risk factor for developing glucose intolerance upon treatment with dexamethasone [35-37]. Although the subject material in our study is limited and therefore caution is warranted in the interpretation of the data, our results suggest that inherent low insulin sensitivity is also a risk factor for developing glucose intolerance if insulin sensitivity is further reduced, although these subjects have a high insulin secretion due to the low insulin sensitivity. This risk could be ascribed to the finding that subjects with low insulin sensitivity have reached a limit for islet adaptation.

The mechanisms underlying the islet adaptation to the reduced insulin sensitivity cannot be established in this study but is of interest since islet dysfunction in impaired glucose tolerance and diabetes may rely on disturbances in these mechanisms. One possibility is that a slight hyperglycaemia has transiently evolved in insulin resistance and this would stimulate insulin secretion. This mechanism is, however, not supported by our present results, since it was the subjects with low insulin sensitivity, i. e. those with lowest adaptative islet response, who developed (slight) hyperglycaemia, whereas those with high insulin sensitivity, i. e. low islet adaptation, did not develop hyperglycaemia. On the other hand, we did not draw samples for glucose analysis during the 2-day period of steroid treatment. A second possibility is that insulin resistance had increased the circulating concentration of non-esterified fatty acids and these had stimulated insulin secretion. This could be a possible phenomenon in relation to diabetes pathophysiology by explaining a subsequent failure of islet function, since longstanding increase in circulating concentrations of non-esterified fatty acids inhibits insulin secretion [38]. A third mechanism could be increased parasympathetic activity, which might be induced by the insulin resistance, in turn increasing insulin secretion. Studies in experimental insulin resistance in animals challenged with a high-fat diet have supported such a mechanism [39]. Finally, a fourth mechanism could involve leptin. The circulating concentration of leptin is increased in obesity and insulin resistance as well as after treatment with dexamethasone [40, 41]. A hypothesis is that leptin mediates the islet adaptation to insulin resistance which is supported by studies showing that circulating leptin concentration correlates with measures of insulin secretion in humans [42]. Leptin is, however, also known to inhibit insulin secretion by direct beta-cell action [43] which instead would indicate that leptin might be involved in the development of islet dysfunction in obesity and insulin resistance. Nevertheless, leptin might be beneficial for islet function in obesity and insulin resistance, since it has been shown that leptin reduces lipid accumulation in islet beta cells which occurs in obesity and this might be beneficial for islet function [44]. Further studies are required to establish the important mechanisms mediating islet adaptation to insulin resistance. Solving these mechanisms might offer not only a new understanding of the physiology of glucose homeostasis but also new targets for the treatment of impaired glucose tolerance and diabetes.

An interesting observation in this study is that glucagon secretion in response to arginine was adaptively reduced by dexamethasone in subjects with high insulin sensitivity, whereas no such reduction was seen in subjects with low insulin sensitivity. In a previous study, we detected a slightly lower glucose inhibition of glucagon secretion in women with impaired glucose tolerance [6]. The present study suggests that the short-term islet adaptation to insulin resistance involves reduction in glucagon secretion in subjects with high insulin sensitivity.

In conclusion, our study provides evidence for a short-term islet adaptation to reduction in insulin sensitivity in healthy postmenopausal women with high insulin sensitivity manifested as increased betacell secretion and inhibited alpha-cell secretion. This resulted in increased fasting insulin concentrations which maintained the baseline glucose. In contrast, in subjects with low insulin sensitivity, the islet adaptation is disturbed, involving both insulin and glucagon secretion. Therefore, although our results need to be confirmed in larger study groups, the study sug- 
gests that low inherent insulin sensitivity is a risk factor for developing impaired glucose tolerance in subjects with normal glucose tolerance due to an inadequate reserve to adapt islet function to a further compromise of insulin sensitivity. The study also emphasises the importance of taking the individual insulin sensitivity into account when studying consequences of changes in insulin sensitivity for insulin secretion.

Acknowledgements. The authors are grateful to L. Bengtsson, U. Gustavsson, E. Holmström and M. Persson for expert technical assistance. The study was supported by the Swedish Medical Research Council (grant no 6834), Ernhold Lundström, Albert Påhlsson and Novo Nordic Foundations, Swedish Diabetes Association, Malmö University Hospital, and the Faculty of Medicine, Lund University.

\section{References}

1. Bergman RN, Phillips LS, Cobelli C (1981) Physiologic evaluation of factors controlling glucose tolerance in man. Measurement of insulin sensitivity and B-cell glucose sensitivity from the response to intravenous glucose. J Clin Invest 68: 1456-1467

2. Bergman RN (1989) Toward physiological understanding of glucose tolerance. Minimal-model approach. Diabetes 38: 1512-1527

3. Kahn SE, Prigeon RL, McCulloch DSK et al. (1993) Quantification of the relationship between insulin sensitivity and beta-cell function in human subjects. Evidence for a hyperbolic function. Diabetes 42: 1663-1672

4. Kahn SE, Prigeon RL, McCulloch DK et al. (1994) The contribution of insulin-dependent and insulin-independent glucose uptake to intravenous glucose tolerance in healthy human subjects. Diabetes 43: 587-592

5. Larsson H, Ahrén B (1996) Islet dysfunction in obese women with impaired glucose tolerance. Metabolism 45: 502-509

6. Larsson H, Ahrén B (1996) Failure to adequately adapt reduced insulin sensitivity with increased insulin secretion in women with impaired glucose tolerance. Diabetologia 39: 1099-1107

7. Ahrén B, Pacini G (1997) Impaired adaptation of firstphase insulin secretion in postmenopausal women with glucose intolerance. Am J Physiol 273: E701-E707

8. Johnston C, Rahgu P, McCullogh DK et al. (1987) B-cell function and insulin sensitivity in nondiabetic HLA-identical siblings of insulin-dependent diabetics. Diabetes 36: 829-837

9. Lillioja S, Mott DM, Spraul M et al. (1993) Insulin resistance and insulin secretory dysfunction as precursors of non-insulin-dependent diabetes mellitus. Prospective studies of Pima Indians. N Engl J Med 329: 1988-1992

10. Ehrmann DA, Sturis J, Byrne MM, Karrison T, Rosenfeld RL, Polonsky KS (1995) Insulin secretory defects in polycystic ovary syndrome. Relationship to insulin sensitivity and family history of non-insulin-dependent diabetes mellitus. J Clin Invest 96: 520-527

11. Swinburn BA, Gianchandani R, Saad MF, Lillioja S (1995) In vivo $\beta$-cell function at the transition to early non-insulin-dependent diabetes mellitus. Metabolism 44: 757-764

12. Cerasi E, Luft R (1967) The plasma insulin response to glucose infusion in healthy subjects and in diabetes mellitus. Acta Endocrinol 55: 278-304
13. Cerasi E, Efendic S, Luft R (1973) Dose-response relation between plasma-insulin and blood-glucose levels during oral glucose loads in prediabetic and diabetic subjects. Lancet 2: 794-797

14. Porte D Jr (1991) $\beta$-Cells in diabetes mellitus. Diabetes 40: $166-180$

15. Beard JC, Halter JB, Best JD, Pfeifer MA, Porte D Jr (1984) Dexamethasone-induced insulin resistance enhances B cell responsiveness to glucose level in normal men. Am J Physiol 247: E592-E596

16. Kahn SE, Beard JC, Schwartz MW et al. (1989) Increased B-cell secretory capacity as mechanism for islet adaptation to nicotinic acid-induced insulin resistance. Diabetes 38: $562-568$

17. Ward WK, Bolgiano DC, McKnight B, Halter JB, Porte D Jr (1984) Diminished B cell secretory capacity in patients with noninsulin-dependent diabetes mellitus. J Clin Invest 74: $1318-1328$

18. Larsson H, Ahrén B (1998) Glucose-dependent arginine stimulation test for characterization of islet function: studies on reproducibility and priming effect of arginine. Diabetologia 41: 1772-1777

19. World Health Organisation (1985) Diabetes mellitus: Report of a WHO study group. Geneva, WHO, Technical Report Series no 727

20. DeFronzo RA, Tobin JD, Andres R (1979) Glucose clamp technique: a method for quantifying insulin secretion and resistance. Am J Physiol 237: E214-E223

21. Cerasi E (1975) Potentiation of insulin release by glucose in man. Acta Endocrinol 79: 511-534

22. Grill V (1981) Time and dose dependencies for priming effect of glucose on insulin secretion. Am J Physiol 240: E24-E31

23. Halter JB, Graf RJ, Porte D Jr (1979) Potentiation of insulin secretory responses by plasma glucose levels in man: evidence that hyperglycaemia in diabetes compensates for impaired glucose potentiation. J Clin Endocrinol Metab 48: $946-954$

24. Kuhl C, Hornnes PJ (1986) Endocrine pancreatic function in women with gestational diabetes. Acta Endocrinol [Suppl] 277: 19-23

25. Sorensen PL, Brelje TC (1997) Adaptation of islet of Langerhans to pregnancy: beta-cell growth, enhanced insulin secretion and the role of lactogenic hormones. Horm Metab Res 29: 301-307

26. Kahn SE, Larson VG, Beard JC, Cain KC, Fellingham GW, Schwartz RS (1990) Effect of exercise on insulin action, glucose tolerance, and insulin secretion in aging. Am J Physiol 258: E937-E943

27. Simonsson E, Ahrén B (1998) Potentiated $\beta$-cell response to non-glucose stimuli in insulin-resistant C57BL/6J mice. Eur J Pharmacol 350: 243-250

28. DePirro R, Bertolli A, Fusco A, Testa I, Greco AV, Lauro $\mathrm{R}$ (1980) Effect of dexamethasone and cortisone on insulin receptors in normal human male. J Clin Endocrinol Metab 51: 503-507

29. Groop PH, Groop LC, Tötterman KJ, Fyhrquist F (1987) The effect of dexamethasone on the enteroinsular axis. Scand J Clin Lab Invest 47: 491-495

30. Ludvik B, Clodi M, Kautzky-Willer A et al. (1993) Effect of dexamethasone on insulin sensitivity, islet amyloid polypeptide and insulin secretion in humans. Diabetologia 36: 84-87

31. Billaudel B, Sutter B (1979) Direct effect of corticosterone upon insulin secretion studied by three different techniques. Horm Metab Res 11: 555-560

32. Barseghian C, Levine R (1980) Effect of corticosterone on insulin and glucagon secretion by the isolated perfused rat pancreas. Endocrinology 106: 547-552 
33. Lambillotte C, Gilon P, Henquin JC (1997) Direct glucocorticoid inhibition of insulin secretion. An in vitro study of dexamethasone effects in mouse islets. J Clin Invest 99: 414-423

34. Ling ZC, Khan A, Delauny F et al. (1998) Increased glucocorticoid sensitivity in islet beta-cells: effects on glucose 6phosphatase, glucose cycling and insulin release. Diabetologia 41: 634-639

35. Wajngot A, Giacca A, Grill V, Vranic M, Efendic S (1992) The diabetogenic effects of glucocorticoids are more pronounced in low- than in high-insulin responders. Proc Natl Acad Sci USA 89: 6035-6039

36. Grill V, Alvarsson M, Efendic S (1992) Dexamethasone treatment fails to increase arginine-induced insulin release in healthy subjects with low insulin response. Diabetologia 35: 367-371

37. Henriksen JE, Alford F, Ward GM, Beck-Nielsen H (1997) Risk and mechanism of dexamethasone-induced deterioration of glucose tolerance in non-diabetic first-degree relatives of NIDDM patients. Diabetologia 40: 1439-1448

38. McGarry JD, Dobbins RL (1999) Fatty acids, lipotoxicity and insulin secretion. Diabetologia 42: 128-138
39. Ahrén B, Simonsson E, Scheurink AJW, Mulder H, Myrsén U, Sundler F (1997) Dissociated insulinotropic sensitivity to glucose and carbachol in high-fat diet-induced insulin resistance in C57BL/6J mice. Metabolism 46: 97-106

40. Ahrén B, Larsson H, Wilhelmsson C, Näsman B, Olsson T (1997) Regulation of circulating leptin in humans. Endocrinology 7: 1-8

41. Larsson H, Ahrén B (1996) Short-term dexamethasone treatment increases plasma leptin independently of changes in insulin sensitivity in healthy women. J Clin Endocrinol Metab 81: 4428-4432

42. Larsson H, Elmståhl S, Ahrén B (1996) Plasma leptin levels correlate to islet function independently of body fat in postmenopausal women. Diabetes 45: 1580-1584

43. Emilsson V, Liu YL, Cawthorne MA, Morton NM, Davenport M (1997) Expression of the functional leptin receptor mRNA in pancreatic islets and direct inhibitory action of leptin on insulin secretion. Diabetes 46: 313-316

44. Shimabukuro M, Koyama K, Chen G et al. (1997) Direct antidiabetic effect of leptin through triglyceride depletion of tissues. Proc Natl Acad Sci USA 94: 4637-4641 